\begin{tabular}{|l|l|l|}
\hline \multicolumn{2}{|c|}{ PublisherInfo } \\
\hline \hline PublisherName & $:$ & BioMed Central \\
\hline \hline PublisherLocation & $:$ & London \\
\hline \hline PublisherImprintName & $:$ & BioMed Central \\
\hline \hline
\end{tabular}

\title{
Visibility of cancer on earlier mammograms in the Finnish breast screening programme
}

\begin{tabular}{|l|l|l||}
\hline \multicolumn{2}{|c||}{ ArticleInfo } \\
\hline \hline ArticleID & $:$ & 3630 \\
\hline \hline ArticleDOI & $:$ & $10.1186 /$ bcr-1999-66608 \\
\hline \hline ArticleCitationID & $:$ & 66608 \\
\hline \hline ArticleSequenceNumber & $:$ & 50 \\
\hline \hline ArticleCategory & $:$ & Paper Report \\
\hline ArticleFirstPage & $:$ & 1 \\
\hline \hline ArticleLastPage & $:$ & 4 \\
\hline \hline & & RegistrationDate : 1999-9-2 \\
ArticleHistory & $:$ & OnlineDate \\
\hline \hline ArticleCopyright & $:$ & Current Science Ltd1999-9-2 \\
\hline \hline ArticleGrants & $:$ & \\
\hline \hline ArticleContext & $:$ & 1305811 \\
\hline \hline
\end{tabular}




\section{Keywords}

False negative, Finland, interval cancer, mammography screening, radiological review

\section{Introduction}

High sensitivity and specificity are essential qualities in a good screening programme. The false negative rate is determined by the experience and skill of the radiologist as well as by breast density and tumour characteristics. Film quality and breast positioning are also important. Review of earlier mammograms of screen-detected and interval cancers allows estimation of the number whose diagnosis could have been advanced to the previous screening test. Radiological and clinical differences may be compared between those that are visible on previous films and those that are not.

\section{Aims}

To determine the frequency with which later-round screen-detected cancers and interval cancers were visible on previous screening films and to compare the radiological and clinicopathological characteristics of those that were visible with those that were not.

\section{Comments}

As expected, the aggressive tumours which would most benefit from early detection are most likely to appear as intervals; those visible on earlier films and then picked up at rescreening are less aggressive, so early detection is of less importance. Also once more the assessment process seems to be a weak point, with $26 \%$ of previously visible cases having undergone assessment in an earlier screening round. Efforts need to focus on increasing screening sensitivity for poor-prognosis cancers and improving pick up rates at assessment.

\section{Methods}


Women aged 50-59 years who were screened in the Tampere region of Finland in the period 1987-92 were included in the study. Screening was by biennial two view mammography with double reading of films. Cancers arising in these women were identified and classified according to diagnosis context (screen detected cancer, interval cancer, non attender etc) by linking screening data to the Finnish Cancer Registry. Clinical and histopathological tumour information was obtained from hospital notes.

Review of mammograms was unblinded and was performed by the radiologist who diagnosed the cancer and thus was aware of its location. Any abnormality at the site of the subsequent cancer was scored as a visible tumour. Statistical testing was by two-tailed Fisher's exact test and chi-squared.

\section{Results}

Of 63,731 women invited, 56,158 (88\%) were screened. Amongst all women, 136 cancers were detected at first round, 52 at second and 25 at third. Additionally 54 cancers arose as intervals between screening invitations and a further nine presented in non-attenders. Previous screening films were reviewed for 76 of 77 incidence screen detected cancers plus 54 intervals (130 cases). Incidence screen tumours were more frequently visible on earlier films than were interval cancers ( $43 \%$ of cases vs $19 \%$, $P=0.002$ ). The main mammographic finding amongst those retrospectively visible (33 of 43 total cases) was most frequently a mass. For both retrospectively visible and invisible cases, screen-detected cancers showed microcalcifications more frequently than did interval cases $(28 \% \mathrm{vs} 8 \%, P=0.003)$. There was little difference in histological type between retrospectively visible and invisible cases, with $73 \%$ of all cases being invasive ductal. However, grade was significantly lower in those retrospectively visible ( $P$ $=0.02$ ) and there was some indication that pathological stage was more favourable. In practice, 41 of 130 reviewed cases $(32 \%)$ benefited from earlier diagnosis. However, if all 43 cancers retrospectively visible on earlier films had been diagnosed at that earlier time, then $65 \%$ (84 of 130) of patients would have benefited, and there would have been 10 fewer interval cancers.

\section{Discussion}

Here 43 of 130 cases (33\%) were visible on earlier screening films. The 'false negative rate' has been found previously to vary between $22 \%$ and $75 \%$ depending upon the number of reviewing radiologists and the method of review used (eg whether blinded or not, whether classification is by consensus or worst case scenario etc). Eleven of the current cases had previously undergone a false negative assessment, nine for the lesion which later presented as cancer. Cancers that were retrospectively visible on earlier films were less aggressive than those that were invisible. Most of these were found at the next screening round and were still small. $(\leq 15 \mathrm{~mm})$. Thus, visibility of incidence screen-detected- cancers on previous screening films may indicate favourable prognosis since these tumours must be slow growing to have been visible at the previous screen. 


\section{References}

1. Saarenmaa I, Salminen T, Geiger U, Holli K, Isola J, Karkkainen A, Pakkanen J, Piironen A, Salo A, Hakama M: The visibility of cancer on earlier mammograms in a population-based screening programme. Eur J Cancer. 1999, 35: 1118-1122. 